\title{
Algoritma dan pemrograman
}

\author{
Nama : Antonio alfarez hidayat \\ Npm : 195120004 \\ Program studi : Tekhnologi informasi \\ Fakultas : komputer \\ Universitas mitra indonesia \\ Dosen : arie setya putra s.kom M.T.I \\ antonio.student@umitra.ac.id
}

Abstract

\begin{abstract}
Algoritma adalah urutan instruksi berurutan, berkat proses tertentu yang dapat dilakukan dan menanggapi kebutuhan atau keputusan tertentu. Algoritma adalah serangkaian langkah yang terurut dan terbatas, yang memungkinkan kita untuk menyelesaikan masalah atau membuat keputusan.Algoritma tidak harus dilakukan dengan bahasa pemrograman, karena algoritma atau flowchart yang sama dapat diwakili dalam bahasa pemrograman yang berbedayaitu adalah pemesanan sebelum pemrograman.Dilihat dengan cara ini, sebuah program tidak lebih dari serangkaian algoritma
\end{abstract}

kompleks yang dipesan dan diberi kode dengan menggunakan bahasa pemrograman untuk kemudian dieksekusi di komputer.

Program adalah himpunan atau kumpulan instruksi tertulis yang dibuat oleh programmer atau suatu bagian executable dari suatu software. Orang yang membuat program sering disebut sebagai pemrograman atau programmer. Aktivitas membuat program disebut sebagai pemrograman.Jadi pemrograman merupakan suatu kumpulan urutan perintah ke komputer untuk mengerjakan sesuatu.

Kata kunci : algoritma dan program 
A. PENDAHULUAN

Materi kuliah setion 01 ini membahas tentang pengertian struktur data

Algoritma merupakan jantung semua program yang merupakan urutan langkah sistematis

Dan dirancang untuk menyelesaikan suatu masalah spesifik dan dengan usaha yang paling minimal. Algoritma berfungsi untuk memecahkan masalah langkah demi langkah Ini adalah serangkaian instruksi yang diurutkan untuk memandu proses tertentu.

Karakteristik algoritma :

- input

- output

- definite (jelas)

- efective

- terminate (berakhir)

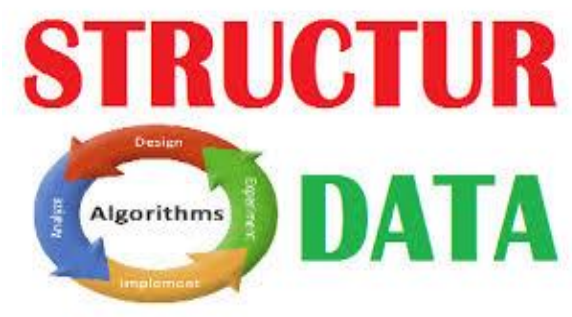

Didalam ilmu

komputer,pemahaman tentang struktuk data yang berkembang selama Ini yaitu,cara menyimpan,mengatur,dan mengelola data dalam media penyimpanan Komputer sehingga data dapat digunakan secara effisien.

\section{B. PEMBAHASAN / STUDI} KASUS

Struktur data adalah cara menyimpan atau merepresentasikan data didalam komputer agar bisa dipakai secara efisien. Sedangkan data adalah representasi dari fakta dunia nyata. Fakta atau keterangan tentang kenyataan yang disimpan, direkam atau direpresentasikan dalam bentuk tulisan, suara, gambar, sinyal atau simbol. Pemakaian struktur data yang tepat didalam proses pemrograman komputer akan menghasilkan algoritma yang lebih jelas dan tepat, sehingga menjadikan program secara keseluruhan lebih efisien dan sederhana.

sedangkan algoritama ialah suatu urutan dari beberapa langkah logis dan sistematis yang digunakanuntuk menyelesaikan masalah tertentu. Algoritma digunakan untuk melakukan penghitungan, penalaran otomatis, serta mengolah data pada komputer 
dengan menggunakan software.

Dalam algoritma terdapat rangkaian terbatas dari beberapa intruksi untuk menghitung suatu fungsi yang jika dieksekusi dan diproses akan menghasilkan output, lalu berhenti pada kondisi akhir yang sudah ditentukan.

Berikut adalah gambar algoritma dibawah ini :

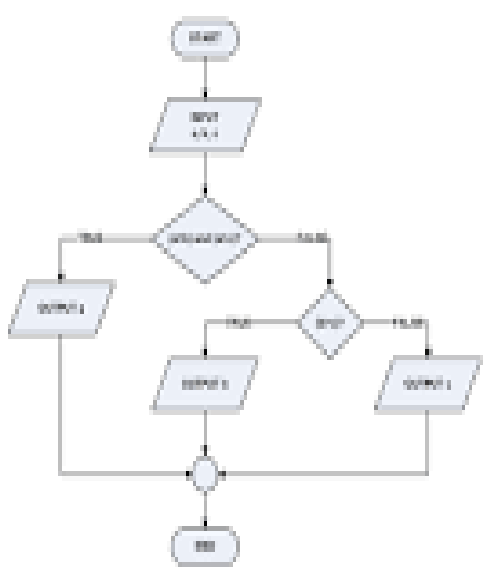

Berbicara soal program,Program adalah sekumpulan instruksi yang diwujudkan dalam bentuk bahasa, kode skema, ataupun bentuk lain, yang apabila digabungkan dengan media yang dapat dibaca

dengan komputer akan mampu membuat komputer bekerja untuk melakukan fungsi-fungsi khusus, termasuk persiapan dalam merancang instruksi-instruksi tersebut. Berikut adalah proses Langkah-langkah pembuatan program :

- defining the problem (definisimasalah)

- planning and design system

- implementasi

- testing

- maintenance

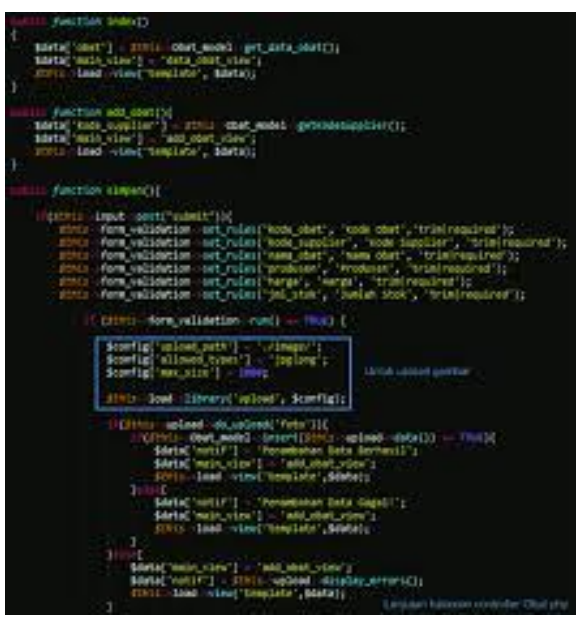

C. ID SECURITY

QWTD4452377-ASP-5244166

D. KESIMPULAN

Dengan algoritma, kita dapat mengatasi masalah dari yang sederhana sampai yang kompleks sekalipun. Namun, seorang user harus mampu membuat suatu program dengan menggunakan bahasa yang difahami oleh komputer. Sebelum disajikan dalam bentuk bahasa pemrogaman, sebaiknya kita membuat diagram alir (Flow Chart) dan Pseudocode. Hal ini dimaksudkan agar dapat mempermudah kerja atau mempermudah dalam membuat program. Selain itu, algoritma dapat mengatasi masalah logika dan masalah matematika dengan cara berurutan, tetapi kadang-kadang algoritma tidak selalu berurutan, hal ini dikenal dengan proses percabangan. 
Dalam algoritma kita harus bisa menguasai

dasar-dasar dari algoritma, menguasai penyelesaian masalah yang paling efisien, dan cepat. Dengan begitu akan sangat mudah mengimplementasikan algoritma yang telah kita kuasai menjadi sebuah program.

- Sedangkan dalam membangun program kita harus memperhatikan huruf referse word,variabel,konstanta,Dan lain-lain karena program $\mathrm{C}++$ bersifat case sensitive (huruf besar dan kecil dianggap berbeda).Program yang paling penting yang berjalan pada komputer. Setiap komputer tujuan umum harus memiliki sebuah sistem operasi untuk menjalankan program lainnya. Sistem operasi melakukan tugas-tugas dasar, seperti mengenali input dari keyboard, mengirimkan output ke layar, melacak file dan direktori pada disk, dan mengendalikan perangkat periferal seperti disk drive dan

printer. Bahasa Pemrograman

Python memiliki kemudahan

tersendiri dalam mengoperasikannya.

\section{E. DISKUSI}

Saya bersama beberapa teman saya yaitu dewi ratna sari,danang kurniawan dan

mega

mendiskusikan bahwa kami

sudah seberapa mengerti untuk

memahami manfaat

mempelajari algoritma

dan pemrograman.selain itu struktur data harus bisa

dipelajari dengan baik agar pada saat pembuatan

program akan lebih mudah karena manfaat strukur data untuk merapikan data,agar data yang disimpan mudah diakses, diubah, dikeluarkan, diha pus,struktur data memiliki beragam jenis tergantung kebutuhan,dan struktur data tersebut.

Sedangkan bahasa

pemrograman merupakan untaian kata-kata berupa instruksi atau perintah-perintah yang biasanya terdiri dari banyak baris yang bisa dimengerti oleh komputer.Bahasa pemrograma wajib dikuasai oleh seorang developer agar dapat membangun sebuah aplikasi atau software. Dan untuk membuat aplikasi tertentu maka digunakan juga bahasa pemrograman yang sesuai dengan kebutuhan aplikasi yang akan dibuat tersebut. 


\section{F. REFERENCE}

[1] O. M. Febriani and A. S. Putra, "Sistem Informasi Monitoring Inventori Barang Pada Balai Riset Standardisasi Industri Bandar Lampung," J. Inform., vol. 13, no. 1, pp. 90-98, 2014.

[2] A. S. Putra, "Paperplain: Execution Fundamental Create Application With Borland Delphi 7.0 University Of Mitra Indonesia," 2018.

[3] A. S. Putra, "2018 Artikel Struktur Data, Audit Dan Jaringan Komputer," 2018.

A. S. Putra, "ALIAS MANAGER USED IN DATABASE DESKTOP STUDI CASE DB DEMOS." A. S. Putra, "COMPREHENSIVE SET OF PROFESSIONAL FOR DISTRIBUTE COMPUTING."

[6] A. S. Putra, "DATA ORIENTED RECOGNITION IN BORLAND DELPHI 7.0."

[7] A. S. Putra, "EMBARCADERO DELPHI XE 2 IN GPUPOWERED FIREMONKEY APPLICATION."

[8] A. S. Putra, "HAK ATAS KEKAYAAN INTELEKTUAL DALAM DUNIA TEKNOLOGY BERBASIS REVOLUSI INDUSTRI 4.0."

[9] A. S. Putra, "IMPLEMENTASI PERATURAN

PERUNDANGAN UU. NO 31

TAHUN 2000 TENTANG DESAIN INDUSTRI 
BERBASIS INFORMATION TECHNOLOGY."

$\begin{array}{lr}\text { A. S. } & \text { Putra, } \\ \text { "IMPLEMENTATION } & \text { OF } \\ \text { PARADOX DBASE." } & \end{array}$

[11] A. "IMPLEMENTATION OF TRADE SECRET CASE STUDY SAMSUNG MOBILE PHONE."

[12] A. S. Putra, "IMPLEMENTATION PATENT FOR APPLICATION WEB BASED CASE STUDI WWW. PUBLIKLAMPUNG. COM."

A. S. Putra, "IMPLEMENTATION

SYSTEM FIRST TO INVENT IN DIGITALLY INDUSTRY."

[14] A. S. Putra, "MANUAL REPORT \& INTEGRATED DEVELOPMENT

ENVIRONMENT BORLAND DELPHI 7.0."

[15] A. S. Putra, "PATENT AS RELEVAN SUPPORT RESEARCH."

[16] A. S. Putra, "PATENT FOR RESEARCH STUDY CASE OF APPLE. Inc."

[17] A. S. Putra, "PATENT PROTECTION FOR APPLICATION INVENT."

[18] A. S. Putra, "QUICK REPORT IN PROPERTY PROGRAMMING."

[19] A. S. Putra, "REVIEW CIRCUIT LAYOUT COMPONENT

REQUIREMENT ON ASUS NOTEBOOK."

[20] A. S. Putra, "REVIEW TRADEMARK PATENT FOR INDUSTRIAL TECHNOLOGY
BASED 4.0."

[21] A. S. Putra, "TOOLBAR COMPONENT PALLETTE IN OBJECT ORIENTED PROGRAMMING."

[22] A. S. Putra, "WORKING DIRECTORY SET FOR PARADOX 7."

[23] A. S. Putra, "ZQUERY CONNECTION

IMPLEMENTED

PROGRAMMING STUDI CASE PT. BANK BCA Tbk."

[24] A. S. Putra, D. R. Aryanti, and I. Hartati, "Metode SAW (Simple Additive Weighting) sebagai Sistem Pendukung Keputusan Guru Berprestasi (Studi Kasus: SMK Global Surya)," in Prosiding Seminar Nasional Darmajaya, 2018, vol. 1, no. 1, pp. 85-97.

[25] A. S. Putra and O. M. Febriani, "Knowledge Management Online Application in PDAM Lampung Province," in Prosiding International conference on Information Technology and Business (ICITB), 2018, pp. 181-187.

[26] A. S. Putra, O. M. Febriani, and B. Bachry, "Implementasi Genetic Fuzzy System Untuk Mengidentifikasi Hasil Curian Kendaraan Bermotor Di Polda Lampung," SIMADA (Jurnal Sist. Inf. dan Manaj. Basis Data), vol. 1, no. 1, pp. 21-30, 2018.

[27] A. S. Putra, H. Sukri, and K. Zuhri, "Sistem Monitoring Realtime Jaringan Irigasi Desa (JIDES) Dengan Konsep Jaringan Sensor Nirkabel," IJEIS (Indonesian J. Electron. 
Instrum. Syst., vol. 8, no. 2, pp. 221-232.

[28] D. P. Sari, O. M. Febriani, and A.

S. Putra, "Perancangan Sistem Informasi SDM Berprestasi pada SD Global Surya," in Prosiding Seminar Nasional Darmajaya, 2018, vol. 1, no. 1, pp. 289-294. 